\title{
A PRODUÇÃO DO ESPAÇO URBANO E O DESENVOLVIMENTO SUSTENTÁVEL: ESTUDO COMPARATIVO ENTRE AS CIDADES DE SÃO JOSÉ DOS CAMPOS E BANANAL (SP)
}

\section{Danielle de Moraes Brandão1 \\ Valéria Regina Zanetti ${ }^{2}$ \\ Cilene Gomes ${ }^{3}$}

\begin{abstract}
Resumo: O presente artigo coloca em pauta o processo de produção e ocupação do espaço urbano nas cidades de São José dos Campos e Bananal, SP, estabelecendo relação entre o passado e o presente desses municípios. Algumas cidades, notadamente as que integram o Vale Histórico, proeminentes na época áurea do café, como é o caso de Bananal, sofreram, no início do século XX, um declínio econômico que se agravou com a instalação da Rodovia Presidente Dutra em 1951. São José dos Campos, que não fez parte do complexo cafeeiro, teve, ao contrário de Bananal, uma ascensão econômica com destaque ao setor industrial a partir da instalação dessa mesma rodovia. O estudo se vale da análise exploratória e comparativa do passado e do presente dessas duas cidades utilizando dados estatísticos do IBGE e imagens do "Google Street View", como forma de entender o processo de urbanização dos dois municípios que tiveram desenvolvimento econômico tão díspares. Observou-se que, na atualidade, o desenvolvimento se dá de forma mais sustentável na cidade de Bananal do que em São José dos Campos, embora economicamente o município de Bananal precise se reestruturar para se estabilizar.
\end{abstract}

Palavras-chave: São José dos Campos; Bananal; Desenvolvimento sustentável, Planejamento Urbano.

\footnotetext{
${ }^{1}$ Mestrado em Planejamento Urbano e Regional/ IP\&D UNIVAP, Brasil. E-mail: daniellebrandao@outlook.com.br.

2 IP\&D/ Universidade do Vale do Paraíba, Brasil. Email: vzanetti@univap.br.

3 IP\&D/ Universidade do Vale do Paraíba, Brasil. Email: cilenegs@univap.br.
} 